\title{
Seasonality of reproduction in gilts and sows
}

\author{
O.A.T. Peltoniemi and J.V. Virolainen \\ University of Helsinki, Faculty of Veterinary Medicine, Department of Clinical Veterinary Sciences, \\ Pohjoinen Pikatie 800, 04920 Saarentaus, Finland
}

In the wild, the pig adapts her reproductive functions according to the seasonal changes in the environment, such as the ambient temperature and availability of food. Like in other short day seasonal breeders, breeding season is favoured in the mid winter in order to provide the offspring with the best chances to survive four months later. Seasonal changes in environment are perceived mainly by the ability of the pig to recognise seasonal changes in photoperiod. This information is mediated through changes in the activity of the pineal gland to secret melatonin, essentially by the same mechanism as reported for other mammals. Stimulation of melatonin receptors located in the hypothalamus has a significant role for the release of $\mathrm{GnRH}$ and subsequent gonadotrophin release from the pituitary. Management and nutrition related factors determine the degree of seasonal effects on reproduction in the commercial piggery environment. Significant improvements in fertility in herds suffering from seasonal infertility are achievable by providing gilts and sows with abundant feed after mating. Attempts to alleviate the seasonal effects on fertility by applying light programs are underway and may lead to significant improvements in productivity of the domestic pig in the long run. Hormonal treatments may be somewhat effective, but not a sustainable solution to seasonal infertility. In conclusion, seasonal infertility is a photoperiod induced phenomenon that can be manipulated by changes in photoperiod and by accounting for season as a significant factor when feeding strategies are applied in commercial piggeries.

\section{Introduction}

The European wild boar is a distinctive short day seasonal breeder with the breeding season commonly occurring in November and December in the Northern hemisphere (Mauget, 1982). Autumn is a season of sexual arrest and building up of energy reserves for the forthcoming winter and pregnancy. Endocrine characteristics include down regulation of gonads and high growth hormone activity. Metabolically speaking, an anabolic autumn with no sexual activity is followed by a catabolic winter and spring, when energy reserves are consumed for growth of foetuses and subsequent lactation. In the wild pig, losing body weight in lactation may be considered as a quite natural phenomenon.

The domestic pig may breed throughout the year; however a tendency for seasonal breeding remains, with the lowest farrowing rate in autumn. This reduction in farrowing rate is evidence for seasonal effects (Peltoniemi et al., 1999a; Tummaruk et al., 2000). Delayed puberty in gilts is a

E-mail: olli.peltoniemi@helsinki.fi 
frequently reported seasonal effect on reproduction in the pig (Paterson et al., 1991). Furthermore, a prolonged weaning to oestrus interval clearly is a major seasonal effect, especially if sows are confined in an individual pen after weaning (Hurtgen and Leman, 1980; Hurtgen et al., 1980; Peltoniemi et al., 1999b). As the seasonal infertility problem was discovered, high ambient temperature was considered as a causative factor (Love et al., 1978). Ever since, a number of studies with a variety of mammalian species demonstrated the central role of natural photoperiod in controlling seasonal breeding (for review see Lincoln et al., 2003; Malpaux et al., 1999). Documentation of the effects of photoperiod on fertility of the domestic pig is not conclusive. Some reports, however, imply that the domestic pig is able to recognise and respond to changes in photoperiod (Paterson and Pearce 1990; Andersson et al., 1998). Furthermore, the earlier confusion about melatonin rhythms of pigs has been clarified and it was also demonstrated that the domestic pig responds to changes in photoperiod in a way similar to other mammalian species in terms of melatonin secretion (Klupiec et al., 1997; Andersson et al., 1998; Tast et al., 2001a, b; Peltoniemi et al., 2005). We also demonstrated that the circadian melatonin profile of the domestic pig is identical to the profile of the European wild boar, and that domestic pigs recognise and respond to changes in natural photoperiod under a conventional piggery environment, which uses the light coming through the windows (Tast et al., 2001a). In sheep, abrupt changes to extremes of photoperiod, a short and a long day, caused the same physiological changes in reproduction as a natural step-wise change in photoperiod (Bittman et al., 1983; Karsch et al., 1984). Because this appears to be the case with the domestic pig as well (Tast et al., 2001b), it should be possible to develop a simplified artificial lighting program to control seasonal variation in reproduction in commercial piggeries.

\section{Seasonal effects on reproductive performance}

Major manifestations of seasonal infertility in gilts and sows are illustrated in Fig. 1. Reduction in the farrowing rate is the most compelling evidence for seasonal effects (Peltoniemi et al., 1999a). Much of the reduction in farrowing rate in summer-autumn has been attributed to a disruption of early pregnancy rather than to conception failure (Love et al., 1993; Peltoniemi et al., 2000a). These sows were mated, they conceived apparently well, and pregnancy was established. The embryos were present for some time, but quite early on, pregnancy was interrupted and the sows returned to oestrus after a prolonged oestrus to oestrus interval (Tast et al., 2002).

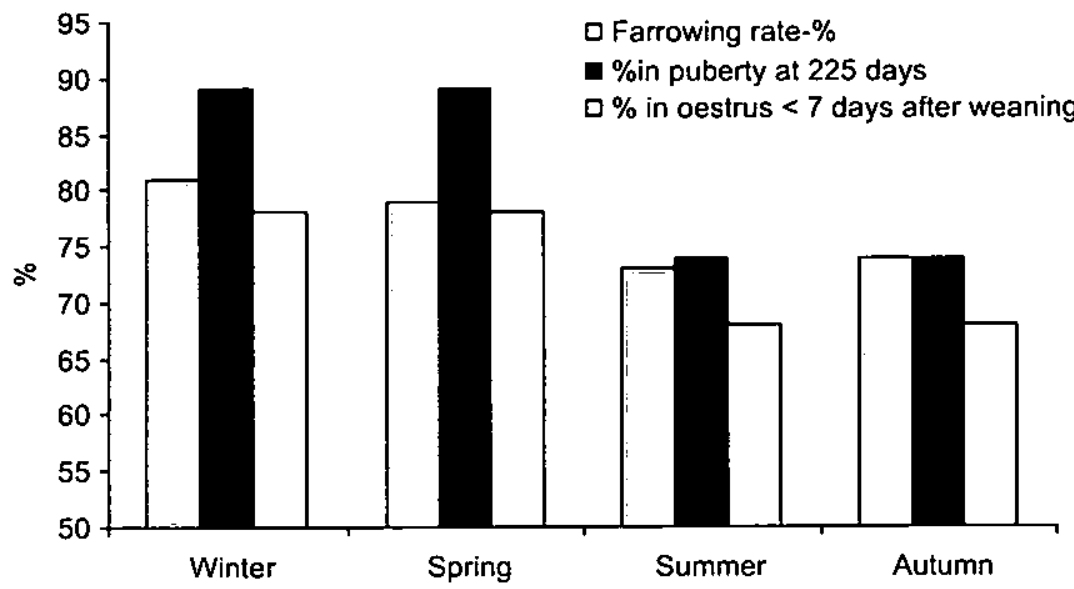

Fig. 1 Major manifestations of seasonal infertility in the pig presented as a percentage for each reproductive parameter. Data pooled from Peltoniemi et al., 1999, Paterson et al., 1991, Hurtgen et al. 1980. 
Among European wild boars, gilts reach puberty only in autumn, as demonstrated by the study of Pepin and Mauget (1989). In the domestic pig, delayed puberty in gilts is a frequently reported seasonal effect on reproduction (Paterson et al., 1991; Love et al., 1993; Gaustad Aas et al., 2004). In a retrospective study of 1081 herds, puberty was delayed by more than 5 days in gilts born between December and April, and therefore, were expected to attain puberty between August and November, (Peltoniemi et al. 1999b). Long days ( $>12 \mathrm{~h}$ ) delayed puberty under standardised field conditions, but the delay was alleviated by boar exposure (Paterson et al., 1991).

A prolonged weaning to oestrus interval clearly is a major seasonal effect, especially if sows are confined in individual pens after weaning (Hurtgen and Leman, 1980; Hurtgen et al., 1980; Peltoniemi et al., 1999b). High ambient temperature reduced voluntary feed intake during lactation in summer-autumn, thereby postponing oestrus after weaning (Prunier et al., 1996, 1997). The prolonged weaning to oestrus interval in summer-autumn, which clearly affects primiparous sows more than older sows (Peltoniemi et al., 1999b), may allow these sows to recover from the metabolic stress imposed by lactation.

The majority of studies indicate that season has no effect on litter size (Love, 1978; Paterson et al., 1978; Mattioli et al., 1987; Reilly and Roberts, 1991; Peltoniemi et al., 1999a), but some other studies suggest a clear seasonal effect, in that litter size was reduced by about one piglet after summer matings (reviewed by Claus and Weiler, 1985). This inconsistency may be due to several conflicting factors, such as an increase in number of return matings in summer-autumn, which would result in larger litters, an increase in number of gilt matings producing smaller litters and an increase in the culling rate, which reduces the number of older less fertile sows, and thus, increases the percentage of successful matings. We found that, although litter size at birth was neither reduced nor increased by season, there was a clear tendency for litters to be larger at weaning during the first half of the year, suggesting a seasonal impact on lactation performance (Peltoniemi et al., 1997b). Such a seasonal effect on lactation performance may be explained by seasonal effects on prolactin secretion (Basset et al., 2001). Reduced litter size is, therefore, a potential manifestation of seasonal infertility and this seasonal effect may be present at birth and at weaning.

\section{Factors underlying seasonal infertility}

Seasonal infertility is generally accepted to be a photoperiod driven phenomenon, however a set of other factors contribute to the annual pattern of seasonality (Figure 2.). These factors include ambient temperature, social interaction between males and females, social interaction between females, housing, feeding strategy, components of feed and genetics.

\section{Photoperiod}

In essence, the pig is considered to be a short day seasonal breeder (Love et al., 1993; Peltoniemi et al., 2000). Sexual activity in autumn is down regulated in anticipation of an unfavourable farrowing season the following winter.

Much of the present understanding about seasonal infertility is still based on the extensive research work carried out with the model short day seasonal breeder, the sheep. In this species, both photoperiodism and circannual rhythm generation participate in regulation of the breeding season (Malpaux et al., 1995, 1998, 1999; Lincoln et al., 2003). Photoperiodism depends on transduction of photoperiod into a nocturnal melatonin signal by the pineal gland that reflects the length of night. Photoperiodic stimuli every $24 \mathrm{~h}$ act to entrain the circadian clockwork of the suprachiasmatic nuclei (SCN). Generation of the circannual rhythm is considered intrinsic 


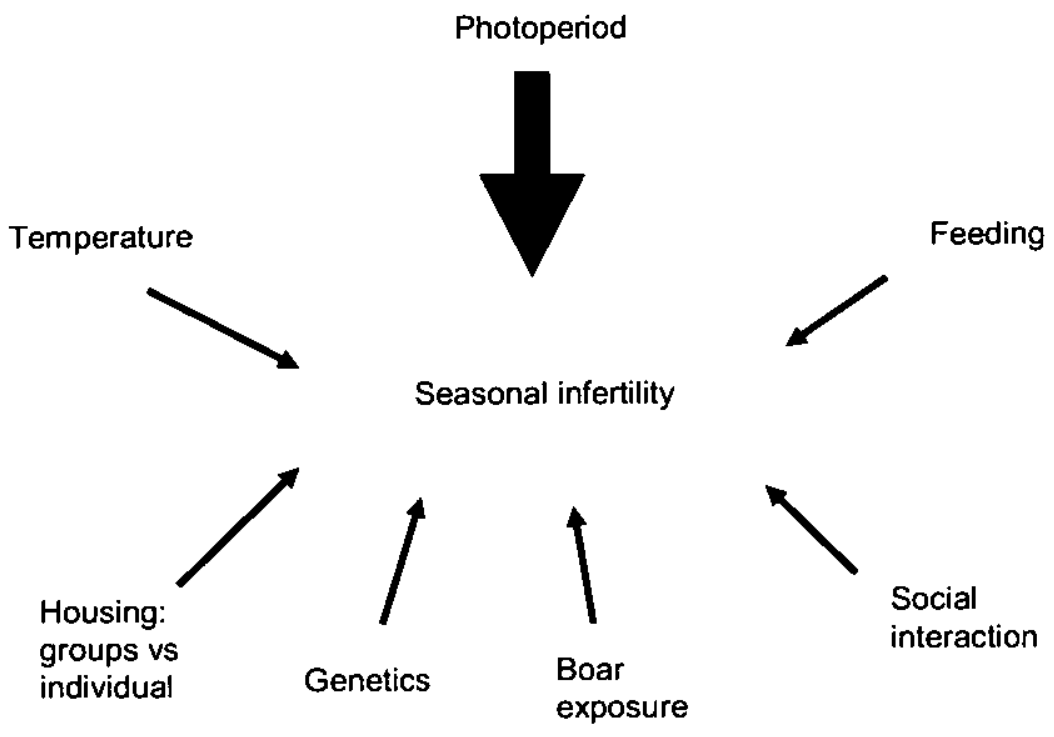

Fig. 2 Factors involved in seasonal infertility. The ambient photoperiod synchronises the intrinsic biological .clock controlling seasonality of breeding activities. A number of other factors determine the degree of seasonality of breeding expressed by the domestic pig.

and functions independently in some mammals (Woodfill et al., 1994; Lincoln et al., 2003), but in the sheep ambient photoperiod may dictate whether or not the long term seasonal activity in reproduction is expressed. Work is currently underway to locate the calendar cells, which control seasonal changes in the gonadotrophin/gonadal axis, however, present evidence implies that these cells are located in the mediobasal area of the hypothalamus (Malpaux et al., 1995, 1998; Lincoln et al, 2002; Lincoln et al., 2003).

There is little evidence to suggest that pigs are different from sheep in the essential mechanism by which season affects reproductive function. Although some confusion exists regarding the existence of a circadian melatonin pattern in the pig (Diekman et al., 1997; Bollinger et al., 1997), recent evidence firmly established that pigs have this pattern (Klupiec et al., 1997; Andersson et al., 1998; Tast et al., 2001a, b; Peltoniemi et al., 2005).

Therefore, it appears likely that the pig is similar to its fellow short day breeder, ungulate sheep, in terms of mechanisms controlling seasonality of reproduction. An intrinsic circannual rhythm, which affects the GnRH pulse generator, is likely to exist and is subject to seasonal changes in photoperiod. Both the intrinsic clock (intrinsic circannual rhythm generation) and photoperiodism are likely to affect the degree of seasonality of reproductive function that is expressed in the pig.

\section{Ambient temperature}

If high ambient temperature was the main factor causing seasonal infertility, one would expect the major effect of season to be a reduction in litter size rather than loss of the whole litter. However, this is not the case because early disruption of pregnancy and subsequent reduction in farrowing rate is clearly the major manifestation of seasonal infertility, and high ambient temperatures in mid summer do not correlate with the major seasonal effect on reproduction. Furthermore, seasonal disruption of pregnancy and reduced farrowing rate is commonly seen at the end of summer and during autumn, when temperatures are not high any more. 
Prunier et al. (1996) demonstrated that high ambient temperature has an impact on voluntary feed intake during long days resulting in negative energy imbalance and prolonged weaning to oestrus intervals in autumn. The same mechanism may cause delayed puberty in gilts in autumn. High ambient temperatures in summer may depress voluntary feed intake of prepubertal gilts, and therefore, delay onset of puberty in autumn (Peltoniemi, 1999). Autumn abortion syndrome appears to be related to low temperatures and individual housing in late autumn or early winter (Almond et al., 1985). This phenomenon was related to high variation in the daily ambient temperature over 24 hours. Affected animals could not compensate for the sudden drop in ambient temperature because their movement was restricted and no bedding material was provided. Sows respond to this situation by aborting the whole litter at any stage of pregnancy.

\section{Feeding}

Availability of feed significantly affects onset of the breeding season in the European wild boar (Mauget, 1982). If feed is readily available and plentiful, the breeding season commences substantially earlier than under adverse nutritional circumstances.

In the domestic pig, the type of housing (individual stalls vs. group housing) and feeding level had a profound effect on fertility of the sow in summer-autumn in two large piggeries in Australia (Love et al., 1995). In the group housing system, restricted feeding increased the weaning to oestrus interval and decreased the farrowing rate by $50 \%$ during summer and autumn (Table 1.). In the winter and spring, the same level of feeding did not adversely affect the weaning to oestrus interval and the farrowing rate remained high (> $85 \%$ ). In contrast, high feeding level had a positive effect on the farrowing rate in summer and autumn. Seasonal infertility was not detected when sows were kept in individual stalls and fed moderately. This appears to be a valid study, because the comparison between groups was carried out under constant management, whereas many other studies have compared housing systems and feeding levels between piggeries, thereby confounding the data.Our recent experiments with early pregnant gilts (Virolainen et al., 2004a,b) and sows (Virolainen et al., 2005b) support the beneficial effect of an abundant feeding level after mating in summer autumn.

Table 1. Effect of type of housing and feeding* level on farrowing rates (Love et al., 1995).

\begin{tabular}{|c|c|c|c|c|c|}
\hline \multirow[t]{3}{*}{ Season } & \multicolumn{5}{|c|}{ Farrowing rate } \\
\hline & \multirow[b]{2}{*}{ Feeding } & \multicolumn{2}{|c|}{ Group housing } & \multicolumn{2}{|c|}{ Individ. stalls } \\
\hline & & Low & Moderate & High & Moderate \\
\hline Summer-Autumn & & 50.0 & 69.0 & 74.1 & 84.0 \\
\hline Winter-Spring & & 87.0 & - & 87.5 & 87.6 \\
\hline
\end{tabular}

*Level of feeding; low - 1.6-2.0 kg/day, moderate $-2.5 \mathrm{~kg} /$ day, high $>3.6 \mathrm{~kg} /$ day $(13 \mathrm{M}) / \mathrm{kg})$. These feeding levels were applied for the first four weeks of pregnancy. Thereafter, the feeding level was $2.5-3.2 \mathrm{~kg} / \mathrm{day}$ for the remainder of pregnancy.

\section{Cenetics}

Differences among sheep breeds in timing and duration of seasonal anoestrus are well documented. Breeds of Merino ancestry (Rambouillet, Dorset) and North European breeds (Finnish Landrace, Romanov) have long breeding seasons, are responsive to ram introduction in spring and perform well outside their natural breeding season (Notter et al., 1985; Thomas et al., 1988; Nugent et al., 1988; Casas et al., 2004). However, selection for less-seasonal lines of sheep has 
not improved reproductive performance. Heritability for spring matings appears to be low. The trait is not expressed until late in life, data records are usually available for females only and the spring breeding trait may only be expressed in particular lambing seasons and management systems (Notter and Cockett, 2005). Therefore, genetic improvement through traditional means seems particularly challenging in the sheep.

The situation is, if possible, even more complicated in the domestic pig. The majority of pig breeds reproduce throughout the year with only a portion of females displaying a tendency for short day seasonal breeding. Seasonal effects on reproduction change from year to year, from one piggery to another, and even, from pen to pen (Love et al., 1993). In the European wild boar, a second breeding season in late spring or early summer may be possible, but is rare.

We compared the genetic background of two wild pig subpopulations on two farms in Finland (Gongora et al., 2003). Both of these farm organizations argued that their animals originate from genuine Wild Boar. The glucose phosphate isomerase pseudogene (GPIP) allele frequency indicated that there was contribution from Asian breeds in subpopulation $A$, which implies crossbreeding with the domestic pig. More conclusively, the same subpopulation also had melanocortin 1 receptor*3 $\left(\mathrm{MC}^{*} \mathrm{R}^{*} 3\right)$ aliele present, indicating distant crossbreeding with the domestic pig. The DNA sequencing technique implied, however, that subpopulation $B$ had only European wild boar related alleles indicating a genuine origin (Gongora et al., 2003).

In terms of seasonality of reproduction, the small genetic difference between subpopulations $A$ and $B$ appears to have a significant impact. Individuals in subpopulation A frequently had a second breeding season in spring with a second litter in summer and sows in subpopulation $A$ were not quite as demanding from the management point of view. In contrast, subpopulation B sows were distinct short day seasonal breeders without any sign of oestrous activity after the spring litter until the next breeding season during the subsequent winter. If farms represented by subpopulation $B$ were given the relatively limited space usually alloted on farms of population $A$, it is highly unlikely that they would successfully reproduce at all (Gongora et al., 2003).

In domestic breeds, clear breed differences in reproductive performance have been noted (Yong, 1992; Yong, 1995), but the seasonal distribution of these differences were rarely reported. In one of our studies (Peltoniemi et al., 1999b), Yorkshire sows had 1.20 times higher risk of rebreeding and Landrace sows had 1.12 times higher risk of rebreeding than crossbred sows. However, the Yorkshire breed performed better than the Landrace and Landrace $x$ Yorkshire crossbreed regarding the weaning to oestrus interval (Peltoniemi et al., 1999b; Tummaruk, 2000). Furthermore, the Yorkshire breed appeared to be more susceptible to seasonal variation in reproduction than the Landrace breed (Tummaruk et al., 2000).

\section{Social interaction and boar exposure}

The olfactory system is used for communication between pigs. Pheromones secreted by the boar have a strong positive effect on oestrous signs in sows. In a study by Pearce and Pearce (1992) sows, which were in oestrus had a stimulating effect on other sows in the same group so that oestrous symptoms within the group became synchronized. Similar synchronization of oestrous symptoms were reported in European wild boar sows by Delcroix et al. (1990). However, pheromones from older sows may have a negative effect on oestrus in younger sows or gilts (Eliasson-Selling et al., 2000). In the summer and autumn, when sows appear more sensitive to a number of adverse effects on fertility, certain pheromones may prevent oestrus and disrupt pregnancy. Pregnancy may terminate in sows or gilts that are of a lower social ranking when too many animals are stocked in a pen. In one of the earlier studies, older pregnant sows caused lower fertility in younger sows housed in the same pen (Wilson and Love, 1990). 
Housing

Group housing led to lower fertility compared to individual stalls or pens in summer-autumn (Hurtgen and Leman, 1980; Love et al., 1995). This was explained by social stress due to competition for feed and a need to defend the social rank in a group housing situation. However, in one of our studies (Peltoniemi et al. 1999a), where management and seasonal effects on fertility were examined on 1,298 pig farms over the period of 1992-1996, a clear reduction in farrowing rate was evident during late summer and early autumn despite the great majority of the sows being housed in individual stalls. This study did not support the earlier studies, in which individual stalls alleviated the reduced farrowing rate in summer-autumn. The management strategies that are essential for achieving good fertility in a loose housing system differ from those followed in piggeries where animals are individually housed. However, if these differences in management, especially in the feeding strategies during early pregnancy, were accounted for, there was no evidence that individual housing per se provided better fertility.

A common strategy recommended and used to compensate for adverse seasonal effects on fertility in the pig industry is to increase the number of females mated. However, as discussed earlier, increasing the stocking density is likely to increase the stress level within the herd, thereby amplifying the seasonal effects on reproduction. In addition, the chances of good fertility results are likely to be compromised, if sows that should be culled from the herd in summerautumn are saved in order to keep the number of animals as high as possible.

\section{Stress}

Wan et al. (1994) proposed the hypothesis that pigs with greater adrenal responsiveness to ACTH are more susceptible to seasonal effects on fertility. The relationship between adrenal responsiveness and seasonal infertility was especially true for gilts, which are known to be more easily affected by season than older sows. This hypothesis implies that environmental factors associated with stress are likely to be important risk factors for seasonal infertility. However, it was shown recently that an acute stress lasting $48 \mathrm{~h}$, and induced during early pregnancy, did not significantly affect embryonic survival and maintenance of pregnancy (Radzan, 2003).

\section{Endocrine basis of seasonal breeding in the pig}

A simplified theory of how short days support and long days tend to depress fertility is presented in Fig. 3. Under long days, photoperiod up regulates the melatonin mediated negative steroid feedback mechanism controlling the $\mathrm{GnRH}$ pulse generator. Therefore, the pituitary LH secretory response is weak, which results in decreased progesterone secretion by the corpora lutea and depressed fertility. On the contrary, short days stimulate pineal gland secretion of melatonin and down regulate the negative steroid feedback mechanism, thus fertility is supported.

\section{Melatonin}

The basis for lighting - melatonin transduction in the pig is thought to be similar to that of other mammals (Tast, 2002). Melatonin affects the $\mathrm{GnRH}$ pulse generator by a mechanism yet to be confirmed for the pig. However, some characteristics of the melatonin response to varying photoperiod related factors were studied in the pig. Light intensity of 40 lx triggered a similar nocturnal melatonin response as a 10,000 Ix environment during the day time (Tast et al., $2001 \mathrm{c})$, suggesting that light intensity may not play a major role in the mechanism by which 


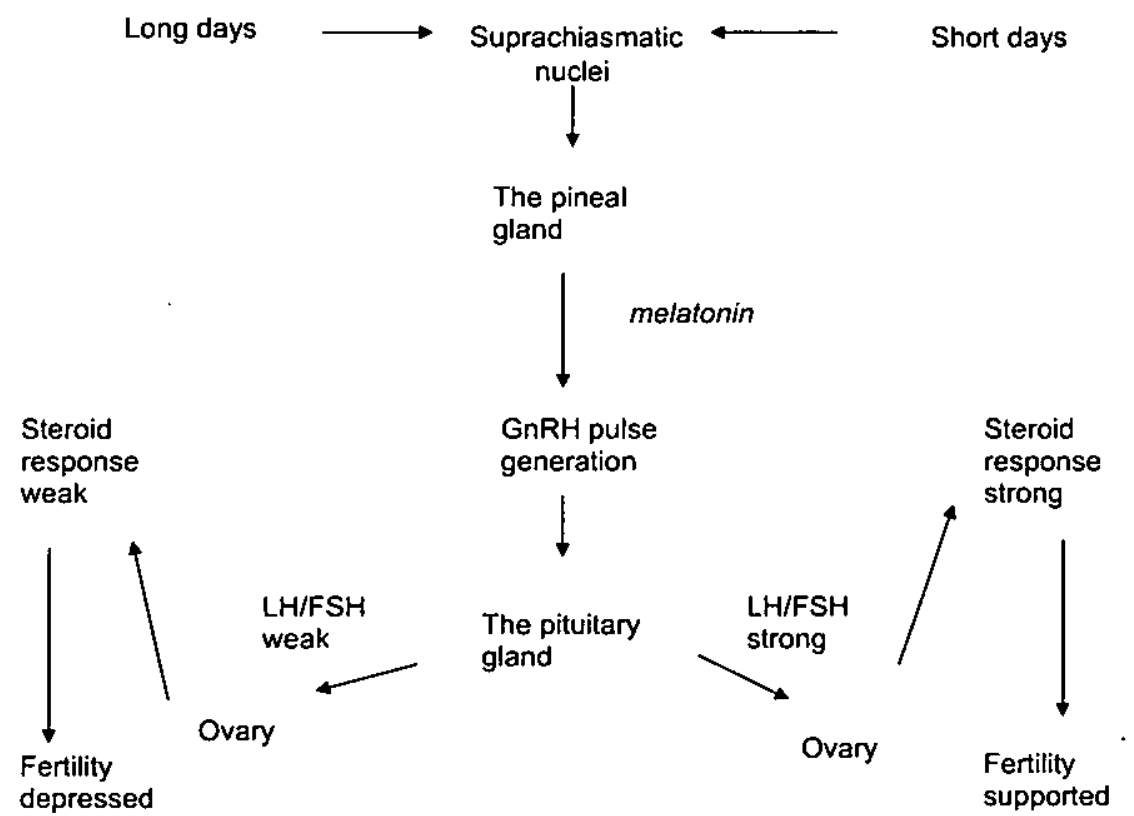

Fig. 3 A schematic presentation of how short days support and long days tend to depress fertility in the domestic pig.

seasonal breeding activities are controlled. Furthermore, a change from one photoperiod to another entrained a corresponding change in the melatonin profile within two weeks in the domestic pig (Tast et al., 2001c). Therefore, it was concluded that it should be possible to develop a lighting program, which supports fertility in the pig, similar to the lighting programs developed to enhance fertility of the other short day seasonal breeder, the sheep (Karsch et al., 1984; Tast, 2002).

\section{Luteinising hormone $(L H)$}

It was shown earlier, that season affects pulsatile LH secretion during early pregnancy in the domestic gilt (Peltoniemi et al., 1997a). These seasonal changes were similar to those during the oestrus cycle. In winter, pulsatile $\mathrm{LH}$ secretion was like that in the mid luteal phase of the oestrus cycle; pulse amplitude was high and the baseline appeared stable. However, in summer-autumn, amplitude of pulsatile LH secretion and the baseline appeared unstable, like in a sow approaching the follicular phase of the oestrous cycle. Definition of a $\mathrm{LH}$ pulse was difficult with the unstable baseline (Peltoniemi et al., 2000b).

Seasonal variation in pulsatile L.H secretion may not be the cause of early loss of embryos in summer-autumn. Manipulation of pulsatile LH secretion disrupted pregnancy if pulsatile LH secretion was suppressed for more than a week rather than for two days only (Peltoniemi et al., 1995, Tast et al., 2000, Virolainen et al., 2004a). Therefore, it appears that a more local component of the effector mechanism disrupting pregnancy at the conceptus-uterine level may play the key role in seasonal infertility.

\section{Progesterone}

The role of pulsatile progesterone secretion during early pregnancy (Virolainen et al., 2005a; Fig. 4.) may be a key element in the mechanism by which season affects pregnancy rate in 

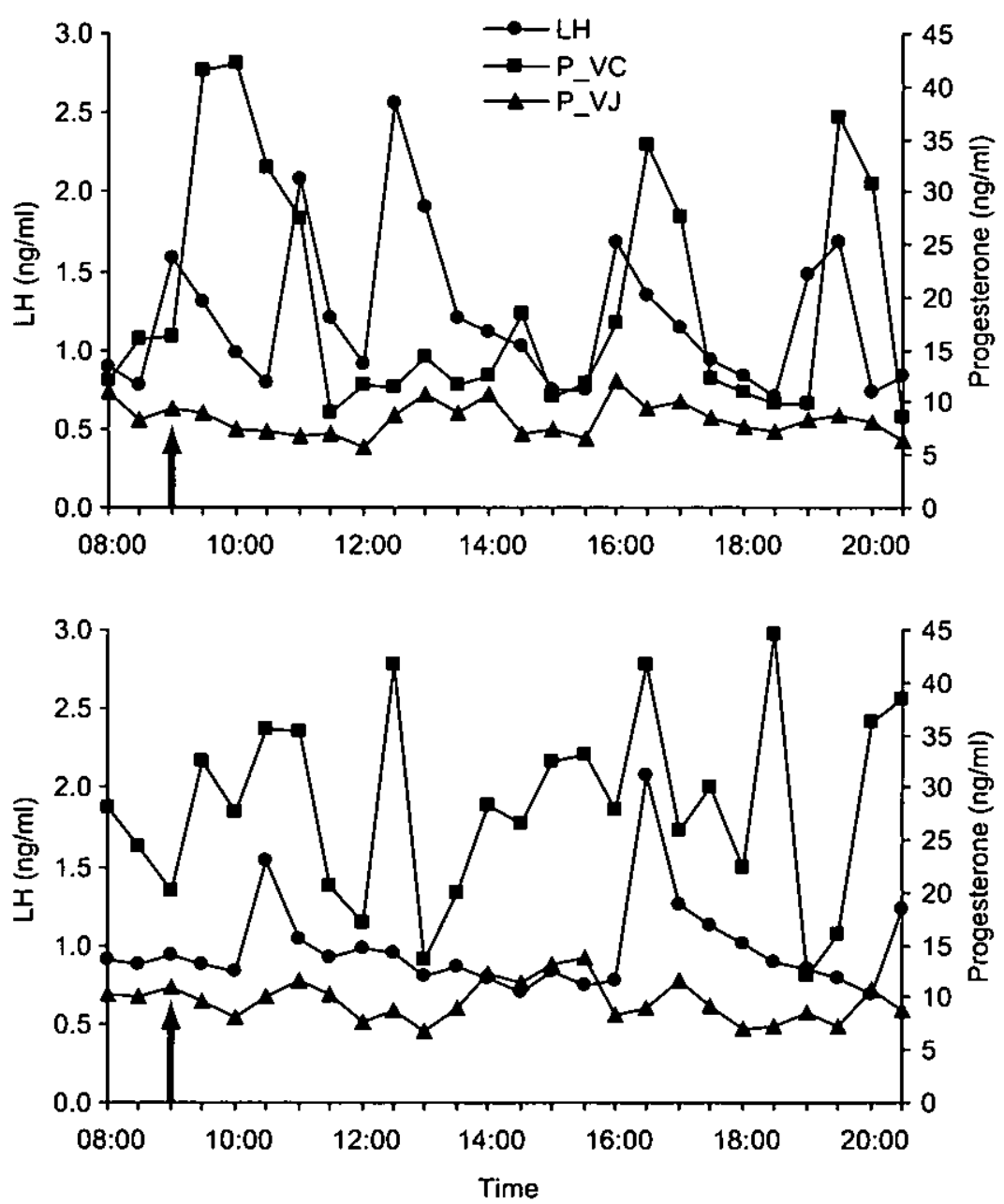

Fig. 4 Plasma progesterone profiles sampled from the caudal vena cava $(P \vee C, a)$ and the jugular vein $\left(P_{-} V J, \Delta\right)$ and plasma luteinising hormone $(\mathrm{LH})$ profiles $(\bullet)^{-}$during a $12 \mathrm{~h}$ bleeding window at $30-\mathrm{min}$ intervals on day 22 of pregnancy for two gilts. Gilt $A$ received a low level of feed starting on day 11 of pregnancy and gilt $B$ received a high level of feed starting on day 20 of pregnancy. Animals were fed once daily after bleeding (shown with arrow) at $0900 \mathrm{~h}$. All of the feed offered was consumed within 10 min by gilt $A$, but not until late afternoon by gilt B. Data from Virolainen et al., 2005.

summer-autumn. Changes in $\mathrm{LH}$ secretion probably influence the local progesterone milieu within the uterus. During early pregnancy, there was no obvious effect of season on baseline progesterone concentration measured in jugular vein blood (Tast et al., 2002). However, the picture became much more complicated if pulsatility of progesterone concentration within the utero-ovarian circulation was accounted for.

An integral of the local progesterone curve may be a much more reliable indication of the progesterone milieu affecting maternal recognition of pregnancy than that provided by a daily measurement of peripheral progesterone. If the local progesterone milieu, as measured by the integral, is inadequate to support the early embryos sufficiently, they may fail to produce the 
second embryonic oestradiol signal required for continuation of pregnancy. Failure of the second oestradiol signal from the embryos caused pregnancy failure and return to oestrus on day 25-35 after mating (Pusateri et al., 1996). Irregular return to oestrus was frequently observed in sows affected by seasonal infertility (Love et al., 1993, Peltoniemi et al., 1999a; Peltoniemi et al., 1999b).

Generally, when progesterone has been a topic in the literature, progesterone in its metabolised form was measured in jugular vein blood or blood from one of the veins in the limbs. However, evidence that metabolised progesterone may not reflect the true progesterone status of the experimental pig is presented in Figure 4 . We sampled gilts from the vena cava caudalis, where progesterone was yet to be subjected to metabolism by the liver.

\section{Keys to avoid the seasonal effects on reproduction in the domestic pig}

Photoperiod is the only factor in common in all reports about seasonal infertility. Whether in the Northern or Southern hemisphere, seasonal infertility appears to be driven by photoperiod. Therefore, there is little doubt that manipulation of photoperiod will eventually be the most effective way of alleviating the detrimental effects of season on reproduction in the domestic pig breeds. Furthermore, consideration of season is important when planning and applying feeding strategies which affect reproduction. In addition, social environment and stocking density are clearly factors of significance. The clear difference in seasonal breeding characteristics between the genuine European wild boar and its crossbred progeny implies that there is a genetic contribution to seasonal infertility. Whether or not the tendency toward seasonal breeding can be avoided by selecting for genes resistant to seasonal effects remains to be explored. Ambient temperatures exceeding the thermal comfort zone are frequently reported to be the cause of seasonal infertility. Thus, cooling devices may prove to be effective. Hormonal treatments may be effective, but are not a sustainable way to control the tendency of the domestic pig towards seasonal reproduction.

We attempted to improve fertility and seasonality of reproduction of the domestic gilt and sow by applying various lighting programs under experimental and field conditions (Tast et al., 2005). Our goal was to build up two "photoperiodic years" within one calendar year; the idea being that short day seasonal breeders may not benefit from being under a constant photoperiod, whether the photoperiod is short or long. In sheep, a constant photoperiod essentially induced refractoriness to the unchanged photoperiod applied (Lincoln et al., 2003).

The attempted lighting program included long days (16 h of light) in the breeding and gestation units and short days ( $8 \mathrm{~h}$ of light) in the farrowing unit to stimulate oestrus after weaning (Tast et al., 2005). In terms of reproductive performance and seasonal infertility, this program was better than the uncontrolled lighting program previously used, but not as effective as a constant long day lighting program. It was postulated that 35 - 42 days under short days prior to moving to the breeding unit was slightly insufficient for a complete reproductive response (Tast et al., 2005), which was based on the assumption that the time needed in the pig is similar to that in the sheep. It is worth noting that $40-50$ days is the minimum period necessary for a photoperiod response in the sheep, and in many seasonality studies, altered lighting was applied for periods of 16 weeks (Lincoln et al., 2002). Another version of the lightning program is therefore currently being explored. In this latest version, an adaptation period of 56 days was applied to sows before moving them into the breeding unit. In this study (Hälli et al., unpublished data), sows kept under short days prior to mating had the best fertility results. Altogether, these studies suggest that fertility of the domestic pig, and especially seasonal variation of fertility can be improved by lighting programs. 
A number of studies demonstrated that seasonal infertility may be avoided by providing gilts and sows with abundant feeding after mating (Love et al., 1995; Virolainen et al., 2004b, Virolainen et al., 2005a, b). The higher pregnancy rates achieved by abundant feeding may well out-weigh the possible disadvantages of reduced embryonic survival following a high plane of feeding after mating as reported by Foxcroft et al. (1997). In any case, providing newly mated or inseminated gilts and sows with roughage feed (hay or straw), to some extent, prevented seasonal effects on reproduction (Peltoniemi et al., 1999a).

The prolonged weaning to oestrus interval due to season may be avoided by group housing sows after weaning instead of keeping them in individual pens. Social interaction between sows and adequate boar exposure are thought to be key elements stimulating oestrus after weaning (Eliasson-Selling et al., 2000). It is true that, under intensive pig production, loose housing may, to some extent, increase the repeat breeding rate (Peltoniemi et al., 1999a). However, this is likely due to limited possibilities for the pig to express species specific behaviour rather than a true negative effect of social interaction on maintenance of pregnancy. If loosely housed sows are given appropriate chances to move around freely and avoid conflicts, they are likely to perform, at least, as well as individually housed sows. Homogenous grouping according to size and age and appropriate use of boars is of fundamental importance to avoid seasonal reduction in reproductive parameters under loose housing conditions (EliassonSelling et al., 2000). In addition, if extra females are to be maintained in preparation of forthcoming autumn, extra care should be taken to avoid too high of a stocking density. In other words, extra animals will require extra space that may require building additional production capacity.

The fact that the ancestor of the present domestic pig breeds is a true seasonal breeder, while her progeny has been domesticated away from distinct seasonal breeding, suggests that further selection may be used to negate seasonal effects on reproduction. As discussed above, crossbreeding of the European wild boar with the domestic pig quickly reduced the distinct tendency for seasonal breeding. In addition, Yorkshire sows are more susceptible to the seasonal reduction in farrowing rate than Landrace sows (Tummaruk et al., 2000). Therefore, it appears feasible that selection against seasonal breeding will be used to improve the reproductive performance of the domestic pig in the future.

Cooling systems designed to decrease either the ambient temperature or skin temperature may prove effective in cases when delayed puberty or prolonged weaning to oestrus interval is the major seasonal effect on fertility on a given farm under a hot climate (Prunier et al., 1996; Peltoniemi, 1999). However, if a reduction in the farrowing rate is the major problem, cooling systems may not be effective (Love et al., 1993; Peltoniemi et al., 2000a). Undernutrition due to heat -induced lose of appetite could retard embryonic growth at early stages of embryonic development, which would negatively affect the embryonic signals required for maternal recognition of pregnancy, thereby interrupting establishment of pregnancy (Findlay, 1993). However, as discussed above, a reduction in farrowing rate is commonly seen later in autumn, when high ambient temperatures may no longer be a problem.

A number of studies have investigated the effectiveness of hormone treatments, such as gonadotrophin analogues, prostaglandins, melatonin and oxytocin to overcome problems with seasonality of reproduction in the pig and sheep (Safranski et al., 1992; Pena et al., 1997; Pena et al., 2000; Pena et al., 2001; Basset et al., 2001). Seasonal anoestrus is considered to be similar to the prepubertal period with regard to the responsiveness of females to exogenous gonadotrophin analogues (Stevenson et al., 1985; Safranski et al., 1992). Therefore, it is not surprising that gonadotrophin analogues appear to be effective in induction of oestrus in seasonally anoestrous gilts and sows. However, although oestrus may have been induced, fertility 
results were not promising (Pena et al., 2001), and an additional caveat is that consumers demand that no hormonal treatments to be used on a routine basis. Therefore, this approach is not a practical sustainable solution to avoiding seasonal effects on reproduction in the domestic pig.

\section{Conclusion}

While the pig has been domesticated indoors, genetically selected for better reproductive performance and provided with environment and feed which enable year around production of piglets, she has retained some of the original circannual rhythm in reproductive function. Farrowing rate, proportion of gilts in puberty at the expected time and proportion of sows in oestrus when expected are lower in late summer and autumn compared to other seasons of the year. Seasonal changes in environment are perceived through seasonal changes in photoperiod and this information is transferred through the SCN and the pineal gland to the $\mathrm{GnRH}$ pulse generator. Eventually, through involvement of the pituitary gonadal axis, seasonal changes in the progesterone environment in the gonadal circulation and within the uterus affect development of the embryos. Seasonal infertility can be avoided by adequate lighting programs involving alternation of short and long days, by providing female pigs with abundant feed, by using breed records for genetic selection and by using cooling systems where the upper thermal comfort zone is exceeded.

\section{References}

Almond CW, Friendship RM and Bosu WTK (1985) Aulumn abortions in sows Canadian Veterinary Journal 26 162-163

Andersson $H$, Wallgren $M$, Rydhmer L, Lundstrom K, Andersson $K$ and Forsberg $M$ (1998) Photoperiodic effects on pubertal maturation of spermatogenesis, pituitary responsiveness to exogenous $\mathrm{GnRH}$, and expression of boar taint in crossbred boars Animal Reproduction Science 54 121-137

Bassett JM, Bray CJ and Sharpe CE (2001) Reproductive seasonality in domestic sows kept outdoors without boars Reproduction 121 613-629

Bittman EL, Karsch FJ and Hopkins JW (1983) Role of the pineal gland in ovine photoperiodism: regulation of seasonal breeding and negative feedback effects of estradiol upon luteinizing hormone secretion Endocrinology $113 \quad 329-336$

Bollinger AL, Wilson ME, Pusateri AE, Green ML, Martin TG and Diekman MA (1997) lack of a nocturnal rise in serum concentrations of melatonin as gilts attain puberty Journal of Animal Science 75 1885-1892

Casas E, Freking BA and Leymaster KA (2004) Evaluation of Dorset, Finn sheep, Romanov, Texel, and Montadale breeds of sheep: II. Reproduction of F1 ewes in fall mating seasons Journal Animal Science 82 12801289

Claus $R$ and Weiler $U$ (1985) Influence of light and photoperiodicity on pig prolificacy. Control of reproduction II In Proceedings of the Second International Conference on Pig Reproduction, held at Columbia, Missouri, U S A, May 1985 185-197
Delcroix I, Mauget $R$ and Signoret JP (1990) Existence of synchronization of reproduction at the level of the social group of the European wild boar (Sus scrofa) Journal of Reproduction and Fertility 89 613-617

Diekman MA, Arthington JA, Clapper JA and Green ML (1997) Failure of melatonin implants to alter onset of puberty in gilts Animal Reproduction Science 46 283288

Eliasson-Selling L, Hofmo PO and Narum $M(2000)$ The art of oestrus control in group-housed sows - a video presentation Proceedings of the 16th IPVS congress, Melbourne, Australia p 395

Findlay JK (1993) Physiology of the uterus and implantation In Manipulating Pig Production Ed. Batterham ES, Australasian Pig Science Association, Attwood, Victoria, Australia pp 235-244

Foxcroft GR (1997) Mechanisms mediating nutritional effects on embryonic survival in pigs Journal of Reproduction Fertility Supplement 52 47-61

Gaustad-Aas AH, Hofmo PO and Karlberg K (2004) Reproductive performance of gilts and sows in temperate versus subarctic and arctic zones of Norway Animal Reproduction Science 80 291-301

Gongora I, Peltoniemi OAT., Tammen I, Raadsma H and Moran C (2003) Analyses of Possible Domestic Pig Contribution in Two Population of Finnish Farmed Wild Boar Acta Agriculturae Scandinavica Section A Animal Science 53 161-165

Hurtgen JP and Leman AD (1980) Seasonal influence on the fertility of sows and gilts Journal of the American Veterinary Medical Association 177 631-635 
Hurtgen JP, Leman AD and Crabo B (1980) Seasonal influence on estrous activity in sows and gilts journal of the American Veterinary Medical Association 176 119-123

Karsch FJ, Bittman EL, Foster DL, Goodman RL, Legan SJ and Robinson JE (1984) Neuroendocrine basis of seasonal reproduction Recent Progress in Hormone Research 40 185-225

Klupiec C, Evans G, Love R] and Kennaway DJ (1997) Clarifying plasma melatonin profiles in domestic pigs: A critical and comparative evaluation of two radioimmunoassay systems Journal of Pineal Research 22 $65-74$

Lincoln G, Messager S, Andersson H and Hazlerigg D (2002) Temporal expression of seven clock genes in the suprachiasmatic nucleus and the pars tuberalis of the sheep: evidence for an internal coincidence timer Proceedings National Academy of Science U S A 99 13890-13895

Lincoln GA, Andersson H and Loudon A (2003) Clock genes in calendar cells as the basis of annual timekeeping in mammals-a unifying hypothesis Journal of Endocrinology 179 1-13

Love RJ (1978) Definition of a seasonal infertility problem in pigs Veterinary Record 103 443-446

Love RJ, Evans G and Klupiec C (1993) Seasonal effects on fertility in gilts and sows Journal of Reproduction \& Fertility - Supplement 48 191-206

Love RJ, Klupiec C, Thornton EJ and Evans G (1995) An interaction between feeding rate and season affects fertility of sows Animal Reproduction Science 39 275-284

Malpaux B, Skinner DC and Maurice $F$ (1995) The ovine pars tuberalis does not appear to be targeted by melatonin to modulate luteinizing hormone secretion, but may be important for prolactin release Journal of Neuroendocrinology 7 199-206

Malpaux B, Daveau A, Maurice-Mandon F, Duarte G and Chemineau $P$ (1998) Evidence that melatonin acts in the premammillary hypothalamic area to control reproduction in the ewe: presence of binding sites and stimulation of luteinizing hormone secretion by in situ microimplant delivery Endocrinology 139 1508-1516

Malpaux B, Thiery JC and Chemineau P (1999) Melatonin and the seasonal control of reproduction Reproduction Nutrition Development 39 355-366

Mattioli M, Prandi A, Camporesi A, Simoni A and Seren E (1987) Investigation on swine summer infertility in Italy. In Definition of the summer infertility problem in the pig, Commission of the European Communities, 33-34, Brussels

Mauget R (1982) Seasonality of reproduction in the wild boar. In: Foxcroft J and Cole R (eds), Control of pig reproduction, Butterworths, London pp 509-526

Notter DR and Cockett NE (2005) Opportunities for detection and use of QTL influencing seasonal reproduction in sheep: a review Genetics Selection Evolution 37 Suppl 1 S39-S53

Notter DR, Lucas JR, McClaugherty FS and Copenhaver IS (1985) Breed group differences in testicular growth patterns in spring-born ram lambs Journal of Animal Science $60622-631$

Nugent RA, III, Notter DR and Beal WE (1988) Effects of ewe breed and ram exposure on estrous behaviour in May and June Journal of Animal Science 66 13631370

Paterson AM and Pearce GP (1990) Attainment of puberty in domestic gilts reared under long-day or short-day artificial-light regimens Animal Reproduction Science 23 135-144

Paterson AM, Barker $I$ and Lindsay DR (1978) Summer infertility in pigs: its incidence and characteristics in an Australian commercial piggery Australian Journal of Experimental Agriculture and Animal Husbandry 18 698-701

Paterson AM, Pearce GP and D'Antuono MF (1991) Seasonal variation in attainment of puberty in isolated and boar- exposed domestic gilts Animal Reproduction Science 24 323-333

Peltoniemi OAT (1999) Seasonal manifestations in reproduction in gilts and sows: experimental and epidemiological studies Thesis, University of Helsinki, Finland

Peltoniemi OAT, Easton BG, Love RJ, Klupiec C and Evans C (1995) Effect of chronic treatment with a GnRH agonist (Goserelin) on LH secretion and early pregnancy in gilts Animal Reproduction Science $\mathbf{4 0}$ 121-133

Peltoniemi OAT, Love R), Klupiec C and Evans G (1997a) Effect of feed restriction and season on $\mathrm{LH}$ and prolactin secretion, adrenal response, insulin and FFA in group housed pregnant gilts Animal Reproduction Science 49 179-190

Peltoniemi OAT, Heinonen M, Tuovinen V, Saloniemi $H$ and Love RJ (1997b) Characteristics of seasonal infertility of the sow in Finland. In Proceedings of the 9th International Congress in Animal Hygiene Ed. Saloniemi, H 1(1), 208-211, Helsinki

Peltoniemi OAT, Love RJ, Heinonen $M$, Tuovinen $V$ and Saloniemi $H$ (1999a) Seasonal and management effects on fertility of the sow: a descriptive study Animal Reproduction Science 55 47-61

Peltoniemi OAT, Heinonen $M$, Leppavuori $A$ and Love R) (1999b) Seasonal effects on reproduction in the domestic sow in Finland-A herd record study Acta Veterinaria Scandinavica 40 133-144

Peltoniemi OAT, Tast A and Love RJ (2000a) Factors effecting reproduction in the pig:seasonal effects and restricted feeding of the pregnant gilt and sow Animal Reproduction Science 60-61 173-184

Peltoniemi OAT, Tast A and Love RJ (2000b) Seasonal, environmental and nutritional effects on gonadotro phins - Implications for establishment and maintenance of early pregnancy in the pig Reproduction in Domestic Animals supplement 6 96-100

Peltoniemi OAT, Tast A, Virolainen IV, Karkamo V, Heinonen $M$ and Andersson MA (2005) Night time melatonin secretion and seasonally delayed puberty in gilts Domestic Animal Reproduction 40 224-227

Pena FJ, Dominguez JC, Carbajo AM, Anel L and Alegre B (1997) Treatment of swine summer infertility syn- 
drome by means of oxytocin under field conditions Theriogenology 49 829-836

Pena FJ, Dominguez JC, Pelaez J and Alegre B (2000) Intrauterine infusion of PCF (2alpha) at insemination enhances reproductive performance of sows during the low fertility season Veterinary Journal 159259 261

Pena F), Gil MC and Pena F (2001) Effect of vulvomucosal injection of D-cloprostenol at weaning and at insemination on reproductive performance of sows during the low fertility summer season under field conditions Animal Reproduction Science 68 77-83

Pepin D and Mauget R (1989) The effect of planes of nutrition on growth and attainment of puberty in female wild boars raised in captivity Animal Reproduction Science 20 71-77

Prunier A, Messias de Braganca M and Dividich LJ (1997) Influence of high ambient temperature on performance of reproductive sows Livestock Production Science 52 123-133

Prunier A, Quesnel $H$, Messias de Braganca $M$ and Kermabon AY (1996) Environmental and seasonal influences on the return-to-oestrus after weaning in primiparous sows: a review Livestock Production Science $45 \quad 103-110$

Pusateri AE, Smith IM, Smith JW, Thomford PJ and Diekman MA (1996) Maternal recognition of pregnancy in swine. I. Minimal requirement for exogenous estradiol-17 beta to induce either short or long pseudopregnancy in cycling gilts Biology of Reproduction 55 582-589

Radzan P (2003) Stress and early pregnancy in sows Thesis, Swedish University of Agricultural Sciences, Uppsala, Sweden

Reilly ID and Roberts Af (1991) An investigation into summer infertility in a commercial pig unit Pig Veterinary fournal $27 \quad 157.168$

Safranski TJ, Lamberson WR and Keisler DH (1992) Use of melengestrol acetate and gonadotropins to induce fertile estrus in seasonally anestrous ewes Journal of Animal Science 70 2935-2941

Stevenson JS, Davis DL and Pollmann DS (1985) Altrenogest and fat for summer breeding of primiparous sows Journal of Animal Science 61 480-486

Tast A (2002) Endocrinological basis of seasonal infertility Thesis, University of Melsinki, Finland

Tast A, Love RJ, Clarke IJ and Evans G (2000) Effects of active and passive gonadotrophin-releasing hormone immunization and establishment of pregnancy in pigs Reproduction Fertility and Development 12 1-6

Tast A, Halli O, Ahlstrom S, Andersson H, Love RJ and Peltoniemi OAT (2001a) Seasonal alterations in circadian melatonin rhythms of the European wild boar and domestic gilt Journal of Pineal Research 30 4349

Tast A, Love RI, Evans G, Telsfer S, Giles R, Nicholls P, Voultsios $A$ and Kennaway DJ (2001b) The pattern of melatonin secretion is rhythmic in the domestic pig and responds rapidly to changes in day length Journal of Pineal Research 31 294-300
Tast A, Love RJ, Evans G, Andersson H, Peltoniemi OAT and Kennaway DJ (2001c) The photophase light intensity does not affect the scotophase melatonin response in the domestic pig. Animal Reproduction Science 65 283-290

Tast A, Peltoniemi OAT, Virolainen JV and Love RJ (2002) Early disruption of pregnancy as a manifestation of seasonal infertility in pigs Animal Reproduction Science 74 75-86

Tast A, Hälli O, Virolainen JV, Oravainen J, Heinonen M and Peltoniemi OAT (2005) An attempt to develop a simplified artificial lighting programme for commercial piggeries to improve fertility of sows Veterinary Record 156 702-705

Thomas GB, Pearce DT, Oldham CM, Martin GB and Lindsay DR (1988) Effects of breed, ovarian steroids and season on the pulsatile secretion of $\mathrm{LH}$ in ovariectomized ewes Journal of Reproduction and Fertility 84 313-324

Tummaruk P, Lundeheim N, Einarsson S and Dalin AM (2000) Reproductive performance of purebred Swedish Landrace and Swedish Yorkshire sows: I. Seasonal variation and parity influence Acta Agriculturae Scandinavica Section A-Animal Science 50 205-216

Virolainen JV, Love RJ, Tast $A$ and Peltoniemi OAT (2004a) Effect of a gonadotrophin-releasing hormone antagonist on luteinising hormone secretion and early pregnancy in gilts Reproduction Fertility Development 15 451-459

Virolainen JV, Tast A, Sorsa A, Love RJ and Peltoniemi OAT (2004b) Changes in feeding level during early pregnancy affect fertility in gilts Animal Reproduction Science 80 341-352

Virolainen IV, Love RJ, Tast A and Peltoniemi OAT (2005a) Plasma progesterone concentration depends on sampling site in pigs Animal Reproduction Science 86 305-316

Virolainen, J.V., Peltoniemi, O.A.T., Munsterhjelm, C., Tast, A. and Einarsson, S (2005b) Effect of feeding level on progesterone concentration in multiparous sows Animal Reproduction Science In press

Wilson MR and Love RJ (1990) The effect of the presence of older females on the maintenance of pregnancy in gilts in the seasonal infertile period. In Proceedings of the International Pig Veterinary Society, p. $442 \mathrm{Ed}$. Scientific Committee of 11 th International Pig Sciences Society Fritz Weibel, Thun

Woodfill CJI, Wayne NL, Moenter SM and Karsch FI (1994) Photoperiodic Synchronization of A Circannual Reproductive Rhythm in Sheep - Identification of Season-Specific Time Cues Biology of Reproduction 50 965-976

Young L.D (1992) Effects of Duroc, Meishan, Fengjing, and Minzhu boars on productivity of mates and growth of first-cross progeny Journal of Animal Science 70 2020-2029

Young LD (1995) Reproduction of F1 Meishan, Fengjing, Minzhu, and Duroc gilts and sows Journal of Animal Science $73711-721$ 